\title{
Overcoming the discourse of science mistrust: how science education can be used to develop competent consumers and communicators of science information
}

\author{
Nancy $\operatorname{Nasr}^{1}$ (D)
}

Received: 4 August 2020 / Accepted: 1 May 2021 / Published online: 21 June 2021

(c) The Author(s), under exclusive licence to Springer Nature B.V. 2021

\begin{abstract}
Science educators can provide learning experiences that challenge notions of mistrust in science, and provide students with the science skills necessary to obtain, evaluate, and communicate credible scientific information. As the COVID-19 pandemic persists, the American public continues to be inundated with messages reinforcing the importance of social distancing, hand-washing and the effectiveness of masks to slow the spread of the coronavirus. While most citizens diligently responded to these recommendations with compliance, there remained subcultures of the American public determined to resist these recommendations and engage in a discourse rooted in a mistrust of science. This discourse of science mistrust was perpetuated through the use of social media, as well as the modeling behaviors of government leaders, particularly as social media posts and news coverage were primary methods of social interaction during mandated stay-at-home orders. The discourse of science mistrust perpetuated during the COVID-19 pandemic reveals that a concerted effort is required by all science educators to aid with overcoming this discourse. Overcoming science mistrust begins in the science classroom by implementing pedagogical opportunities for science students to obtain, evaluate, and communicate scientific information. Allowing students to obtain and evaluate information are a critical skill to develop in the science classroom as science educators aim to produce competent consumers of scientific information. Furthermore, science students ought to also have experience with the skills associated with communicating scientific information. Communicating scientific information is a critical skill for science students to develop as it is through the effective communication of credible scientific information that the discourse of science mistrust can be overcome. Providing these learning opportunities to science students empower students to effectively evaluate social media and news coverage associated with the COVID-19 pandemic, and promote a future, wherein citizens are able to read, interpret, and critically consume scientific information to overcome discourses of science mistrust.
\end{abstract}

Keywords COVID-19 $\cdot$ Mistrust $\cdot$ Information $\cdot$ NGSS

Nancy Nasr

nnasr@ghctk12.com

1 Granada Hills Charter High School, 10535 Zelzah Ave, Granada Hills, CA 91344, USA 
The COVID-19 pandemic that began in 2020 brought with it stay-at-home orders, loss of life, and a social perpetuation of a mistrust of science. As the COVID-19 pandemic persists, the American public continue to be inundated with messages reinforcing the importance of social distancing, hand-washing and the effectiveness of masks to slow the spread of the coronavirus. While most citizens diligently responded to these recommendations with compliance, there remained subcultures of the American public determined to resist these recommendations and engage in a discourse rooted in a mistrust of science. Ben Charoenwong, Alan Kwan, and Vesa Pursiainen (2020) describe these subcultures as those including populations with low education levels, higher shares of Donald Trump voters, and climate change deniers. Joanne Miller (2020) further asserts that these subcultures generally believe "that the threat of COVID-19 has been exaggerated to damage President Trump" (p. 319), and that the "virus was purposefully create and spread" (p. 319). As a result of the political conspiracy theories perpetuated in these subcultures, ignoring public health recommendations, such as the use of masks to slow the spread of COVID-19, became a partisan statement. In fact, these beliefs became further proliferated in subgroups of these subcultures as their beliefs, values, and norms ultimately negated the recommendations associated with public health safety. Following general compliance with initial stay-at-home orders, pressure mounted for government officials to re-open businesses, beaches, and restaurants, as those who mistrusted scientific recommendations to remain closed urged a return to normal. Buckling to this pressure, governors, in states such as California where early stay-at-home orders were instituted, developed plans to re-open communities. What followed was a rampant increase in the number of coronavirus cases and deaths, such that the COVID-19 pandemic flung the American public into a state of uncontrolled vulnerability to affliction. The purpose of this paper is to suggest ways in which science educators can provide learning experiences that might challenge notions of mistrust in science, and provide students with the science skills necessary to obtain, evaluate, and communicate credible scientific information.

Philip Ball and Amy Maxmen (2020) assert that the result of premature re-opening plans was due in large part to the extensive spread of coronavirus misinformation. Scientists asserted that some Americans were blatantly in favor of ignoring recommendations for public safety rooted in science because of a deep mistrust of the motives, agendas, and credibility of scientists. As the discourse of science mistrust deepened, so too did the bleakness with which the US could combat the coronavirus. As the numbers of cases and those mourning loved ones grew, the situation revealed that any future crises requiring stewardship from scientists would ultimately fail if the mistrust of scientists was not sufficiently addressed. Instead of viewing scientists through a lens of mistrust, action must be taken to ensure that the public at large view scientists as credible scholars whose contributions to public safety are rooted in the health and well-being of all. Wendy Parmet and Jeremy Paul (2020) indicate that overcoming beliefs rooted in science mistrust are difficult to change, particularly for those whose beliefs have remained unchallenged for extended lengths of time.

Indeed, some subcultural groups' beliefs and values ultimately trump concerns for public health, and proliferate science mistrust. Church goers who refuse to refrain from large religious gatherings, anti-vaxxers who protest receiving a coronavirus vaccine, and toxic White males who disdainfully disregard masks, all highlight instances wherein subcultural group beliefs form the foundation of unsafe public health behaviors, because of an underlying mistrust of science. Adebola Adegboyega et al. (2020) argue that from a socio-behavioral perspective gathering in church is a crucial component of Christian worship, as it is believed that church gatherings "facilitate spiritual growth" (p. 9), and that 
without these gatherings "the spirituality and religiosity of some congregants may [be] abruptly stalled" (p.9). With this in mind, Christians who firmly believe that the act of gathering is a necessary tenet of the faithful might have difficulty adhering to social distancing measures aimed at protecting public health, and believe that cessation of church gatherings is a direct byproduct of the untrustworthy agendas of scientists. John Ashton (2021) also describes the difficulty for anti-vaxxers to overcome their beliefs about the COVID-19 vaccine, despite the vaccine being an overwhelmingly welcome development in the fight against COVID-19. Anti-vaxxers' primary arguments against the value and use of a COVID-19 vaccine include the notion that vaccination is "un-Christian, that it is an infringement of personal liberty and that it is part of a more general suspicion of scientific medicine" (p. 42). These beliefs are certainly difficult to overcome, particularly, if they are rooted in a mistrust of society's motives and a mistrust of science. Finally, Jayson Harsin (2020) describes how toxic White masculinity proliferates science mistrust in the context of COVID-19. Perhaps one of the most notable displays of toxic White masculinity surfaced in Donald Trump's repeated refusal to wear a mask as a public safety measure aimed at reducing the spread of the coronavirus. Harsin (2020) asserts that such examples of toxic White masculinity are byproducts of "emo-truth" which is "a particular form of aggressive masculine performance of trustworthiness, corresponding to a code for recognizing it, resulting in a legitimated status of the popular truth-teller, and at odds with more official scientific, institutional truth-tellers" (p. 1062). In fact, toxic White males who refuse to wear a mask perpetuate the general mistrust of science that thrives as a result of "emotruth", particularly as these anti-maskers "scorn dialogue and listening" (p. 1063) and believe conformity to public safety measures poses a threat to their perceived masculinity. Though the subcultural beliefs of groups such as anti-vaxxers and toxic White males complicates efforts to overcome pervasive mistrust of science, our science students still remain a viable target to proliferate trust in science.

\section{How science mistrust was perpetuated during the COVID-19 pandemic}

\section{Social media}

The COVID-19 pandemic presented a sociocultural experience unlike any other in recent history. From isolating stay-at-home orders to civil rights demonstrations to a near constant onslaught of media attention devoted to grim statistics, the COVID-19 pandemic presented a marked change in how citizens consumed and shared information. A.K.M. Najmul Islam et al. (2020) assert that while following stay-at-home orders, more people were faced with the challenge of finding social connection with their peers, and as a result more people turned to social media to remain in social contact with others. Social media platforms such as Facebook, Instagram, and Twitter became spaces for sharing information, discussing current events, and, for some, engaging in discourses of science mistrust. From memes to tweets, social media became a breeding ground for those choosing to perpetuate discourses of science mistrust, and emboldened those who were determined to buck recommendations from scientific experts in favor of practices and behaviors that did not promote public safety. Several notable examples of social media posts emerged that perpetuated the discourse of science mistrust and fueled the notion that the coronavirus was a hoax designed to infringe on citizens' basic civil rights. Moreover, as Aengus Bridgman et al. (2020) indicate, those who use social media platforms as a means to obtain and disseminate 
information are more likely to be misinformed about the COVID-19 pandemic than those who use alternative sources of information.

One prominent theme in these social media posts is the notion that the measures being suggested by scientists to contain the pandemic are in fact measures designed to limit personal freedoms and institute greater compliance with a system that ultimately seeks to monitor our movements. Figure 1 shows a social media meme that attempts to instill a fear of mask compliance, as this will eventually lead to greater compliance with measures that seek to limit our personal freedoms and our privacy. In effect, the message that mask wearing will inevitably lead to oppression of personal freedoms negates scientific assertions made by Steffen Eikenberry et al. (2020) indicating that mask wearing is an effective way to slow the spread of the coronavirus.

Similarly, Fig. 2 alleges that compliance with mask wearing and social distancing is synonymous with robotic submission to a system that seeks to limit our autonomy. Both of the social media memes shown in Figs. 1 and 2 attempt to discredit science, not as a field to be trusted, but rather as a body of knowledge designed to justify governmental agendas aimed at depriving people of their autonomy and thereby perpetuating a discourse of science mistrust.

\section{Government leadership}

Sherman Lee (2020) indicates that the COVID-19 pandemic led to significant anxiety for the public such that civilians sought direction, guidance, and even comfort from government leaders of all levels. Notably, the President of the United States Donald Trump was thrust into the spotlight and his presidency faced its most challenging leadership test, as his national guidance was sought to keep Americans safe during a public safety crisis. Governors to mayors to ordinary citizens expected a president who would lead

Fig. 1 Social media meme connecting mask compliance with ultimate infringement on personal freedoms and privacy

\section{LET ME EXPLAIN WHERE THIS IS GOING...}

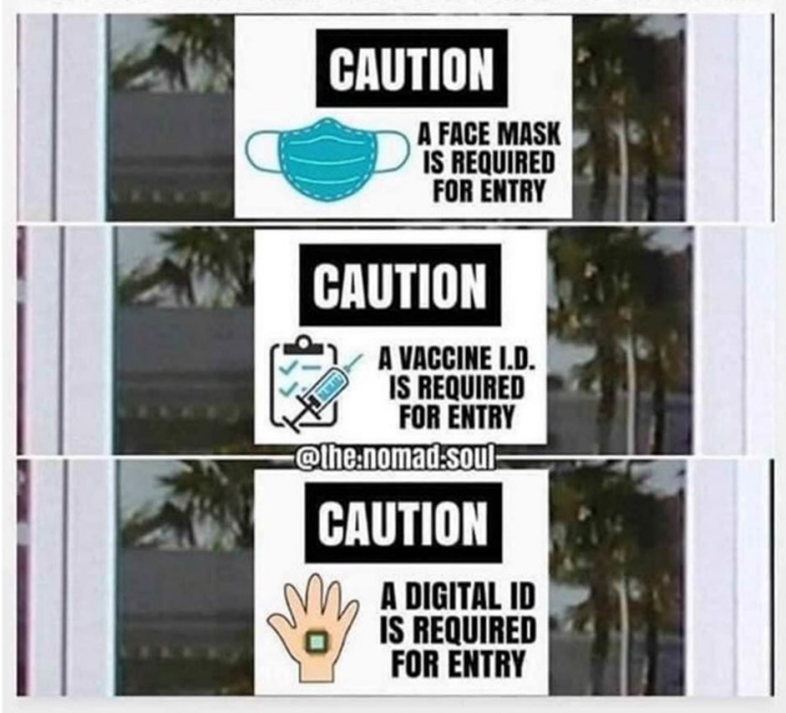




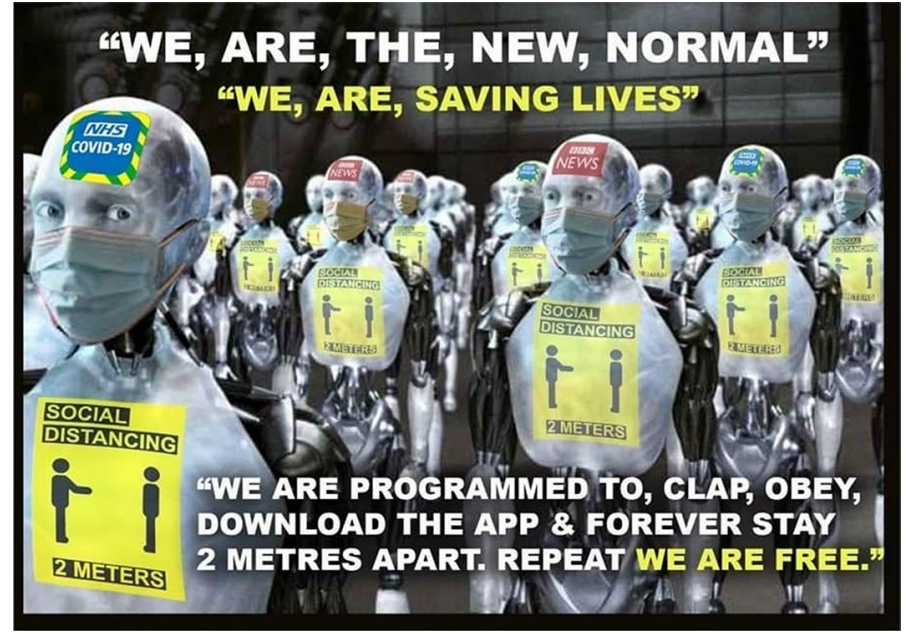

Fig. 2 Social media meme relating COVID-19 safety measures with a fear of limited personal autonomy

the US into the COVID-19 battle and help Americans emerge victorious by containing the spread of the virus, providing ample personal protective equipment for frontline medical workers, and developing a plan to re-open communities safely. Instead, Americans were led by a president whose leadership style prioritized disseminating misinformation, censoring the public's access to credible scientific information, and even blatant discrediting of top infectious disease scientists.

According to the website Union of Concerned Scientists (https://www.ucsusa.org/) several reports linking Donald Trump's presidency to attacks on science emerged throughout the course of the COVID-19 pandemic. As the Union of Concerned Scientists (2020) indicate in their blog post entitled "Trump Administration Ignores CDC Scientists on COVID-19 Temperature Screenings", representatives from the Centers for Disease Control (CDC) describe the way in which their efforts to present the facts regarding the scientifically proven ineffectiveness of temperature checks to screen people for coronavirus were ignored by the White House. Despite being presented with scientific evidence, the Trump administration chose to publicly ignore the scientific efforts of a federal body of scientists, thereby perpetuating a discourse of science mistrust, particularly among supporters of the administration.

The Union of Concerned Scientists (2020) further indicate in their blog post "For Coronavirus Federal Scientists are Restricted in What They Can Say to the Public" that all federal health officials and scientists are required to coordinate statements and public appearances related to the COVID-19 pandemic with the White House. Doing so in effect censors the public's access to credible scientific information, thereby allowing the White House to disseminate potentially misleading information, and implicitly demonstrates the administration's mistrust of science to educate and guide the American public with respect to appropriate coronavirus response measures. The administration's perceived mistrust of science and scientists ultimately results in a trickling down of this mindset to citizens who assume that the administration has their best interests in mind when handling the COVID-19 pandemic. 
Josh Lederman and Kelly O'Donnell (2020), writing about Dr. Anthony Fauci, showed how the White House attempts to discredit his scientific expertise. A statement released by the White House in July 2020 expressed concern over "the number of times Dr. Fauci has been wrong on things", and also questioned the credibility of statements made by Fauci in early 2020 regarding the seriousness of the coronavirus. These attempts to discredit Fauci further fanned the flames of science mistrust, particularly at a time when subcultures including those with lower education levels, higher shares of Trump supporters, and toxic White males became increasingly restless and resistant to local mandates put in place to protect the health and safety of citizens. Questioning the credibility of Fauci served to further promote the discourse of science mistrust as government leaders were implicitly capitalizing on the growing frustration of those resistant to safety mandates and encouraging them to funnel their frustrations toward those in positions of scientific authority.

\section{Helping students overcome the discourse of science mistrust}

\section{Developing competent consumers of scientific information}

Social media and government leadership play a central role in the dissemination of inaccurate scientific information, as well as the perpetuation of the discourse of science mistrust. Identifying instances of the discourse of science mistrust in the context of the COVID-19 pandemic reveal that a concerted effort is required by all science educators to aid with overcoming this discourse. It is important to note, however, that while science education is important to aid with overcoming this discourse, it is not enough to change the mindset of subcultural groups whose beliefs are anchored in science mistrust. Instead, science education provides society with a "starting point" to address the discourse of science mistrust for future citizens and consumers of scientific information. Furthermore, science students' classroom experiences represent only a small cross section of their life experiences. In light of this, it is imperative for science educators to be mindful of the notion that some of the students they teach might in fact be members of subcultures whose beliefs, norms, and values are rooted in discourses of science mistrust. With this consideration in mind, science educators might appreciate the pedagogical strategies presented in this paper as a means to challenge the subcultural beliefs of such students, and promote critical thinking intended to overcome discourses of science mistrust.

Overcoming the discourse of science mistrust begins in the science classroom by implementing pedagogical opportunities for science students to obtain, evaluate, and communicate scientific information. Sihan Xiao and William Sandoval (2020) argue that providing these learning opportunities can aid with overcoming the discourse of science mistrust as "curiosity about science, self-confidence about dealing with science, and expectations regarding the value of scientific knowledge in society [are] key attitudinal elements in critically evaluating information in science-related news reports" (p. 250). These learning opportunities must emphasize critical thinking in the context of scientific information, and the Next Generation Science Standards (NGSS) provide science educators with a means to deliver such rigorous, meaningful learning opportunities.

The NGSS constitute a three-dimensional approach to science learning, wherein students not only learn the content of the science disciplines, but also explore central themes that are common to all of the science disciplines, and engage in authentic construction of scientific knowledge by applying eight science and engineering practices (SEPs) (NGSS 
Lead States 2013). The eight SEPs are included in the NGSS as a way to promote the development of science literate students who fundamentally understand how scientific knowledge is produced. Of these eight SEPs, obtaining, evaluating, and communicating information is a critical component of science knowledge development as this practice relies on the ability for scientists to evaluate the validity and reliability of claims (NGSS Appendix F 2013), and thus, is a crucial learning component for science teachers wishing to help their students overcome the discourse of science mistrust.

The NGSS specify that allowing science students to obtain, evaluate, and communicate information require them to "read and synthesize information from multiple appropriate sources and assess the credibility, accuracy, and possible bias of each publication" (NGSS Appendix F 2013, p. 65). In effect, Shawn Stover and Michelle Mabry (2020) indicate that providing science students with multiple classroom opportunities to evaluate scientific texts for their reliability instills a sense in students that the information presented in texts should always be approached skeptically until it is assessed for its credibility, accuracy, and possible bias. For example, science students may be unaware of the peer-review process required for credible scientific publications and thus, inquiring whether or not a particular publication is peer-reviewed may help science students understand that scientific misinformation may be disseminated primarily from non-peer-reviewed sources, thereby perpetuating the discourse of science mistrust. In fact, an online graphic published by Reuters (Bhatia and Collet-White 2020) shows that out of 153 studies published on coronavirus in early 2020 , only 61 of them were peer-reviewed. With only 61 peer-reviewed studies, it becomes more evident for students that many sources of scientific information related to coronavirus may in fact be unreliable, and ultimately used to perpetuate a discourse of science mistrust.

Karenann Jurecki and Matthew Wander (2012) reinforce the benefit and value of the use of peer-reviewed articles in their two-tier approach to helping students evaluate scientific information. Jurecki and Wander's (2012) two tier approach encompasses a "set of criteria for evaluating scientific literature that can be used in traditional and nontraditional learning environments" (p. 102). The first of the two-tiers requires students to determine if the source of scientific information is "original scientific research....and published in an authoritative source" (p. 102). As described above, it is important that science teachers emphasize the credibility of peer-reviewed articles, and where to locate peer-reviewed articles, as these articles constitute both original research and are published in authoritative sources. The second tier "encourage[s] students to read scientific materials for the quality of the information, not just the quality of the source" (p. 102). In other words, students must read scientific information and assess whether or not the information presented is in fact free of bias, and whether or not the conclusions presented are based on sound scientific principles. Jurecki and Wander (2012) acknowledge that the second tier requires science students to engage in critical thinking, which is an expected goal of science instruction in the context of the NGSS.

The SEP of obtaining, evaluating, and communicating information requires students to not only evaluate source for their credibility and accuracy, but also for their potential bias. Dale Benos et al. (2005) describe several ethical breaches in scientific publication, and one of those breaches is that of conflict of interest. Benos et al. (2005) describe conflict of interest as a situation in which an author of a scientific publication has underlying motivations related to "political affiliation, religious conviction, and personal relationships" that threaten the objectivity and ability of the scientist to present information in an honest way. Benos et al. (2005) stress that when scientists hold such conflicting interests "the information reaching the scientific community and the general public could be distorted and potentially devastating" (p. 65). It is important for science teachers to emphasize that 
successfully evaluating scientific information requires students to reflect on the potential conflicts of interest or biases of the authors presenting the material.

For example, the COVID-19 pandemic led to a marked shift in the research community, wherein greater numbers of research studies were published to better understand the coronavirus, how it is spread, and how people previously infected with the virus ultimately recover. Eran Bendavid, Bianca Mulaney, Neeraj Sood, Soleil Shah, Emilia Ling, Rebecca Bromley-Dulfano, Cara Lai, Zoe Weissberg, Rodrigo Saavedra-Walker, Jim Tedrow, Dona Tversky, Andrew Bogan, Thomas Kupiec, Daniel Eichner, Ribhav Gupta, John Ioannidis, and Jay Bhattacharya (2020) conducted a study at Stanford University to monitor the prevalence of people with coronavirus antibodies in Santa Clara, California. The findings of the study suggested that antibody prevalence is more widespread than previously thought which indicates that the virus is not as lethal as being described in the media, and thus communities ought to return to normal economic operations. Later, according to Gabby Landsverk (2020), it was discovered that the study was in fact partially funded by John Ioannidis, the founder of JetBlue airlines, and a corporate businessman who has been very vocal in his desire for businesses to return to normal operations during the pandemic. In effect, Ioannidis had a significant conflict of interest in the study, wherein his primary interest was in the profitability of his business, rather than the safety of the public. This example demonstrates the need for science educators to expose their students to the notion of conflicts of interest in research and use that understanding of conflict of interest to scrutinize the validity and reliability of presented scientific information.

\section{Promoting effective scientific communication}

Obtaining and evaluating information is a critical skill to develop in the science classroom as science educators aim to produce competent consumers of scientific information. However, in addition to obtaining and evaluating information, science students ought to also have experience with the skills associated with communicating scientific information. Communicating scientific information is a critical skill for science students to develop as it is through the effective communication of credible scientific information that the discourse of science mistrust might be overcome. Throughout the course of the COVID-19 pandemic, American citizens were bombarded with media information related to the spread of the coronavirus, statistics associated with case numbers and deaths, and scientific reports associating the pandemic's outlook as a construct of health safety measures being appropriately followed. In fact, as the COVID-19 pandemic swelled in the US, an interesting relationship emerged; the relationship between scientists and journalists.

Penelope Canan and Melanie Hartman (2007) explore what they call the "science-journalism collaboration" and describe it as a "respected [pillar] within democratic societies because the products of their enterprise are appreciated as contributing to social life" (p. 167). In effect, the relationship between science and journalism becomes critical, particularly during events associated with public health crises, as "the public receives most of its scientific information from journalists, in print and broadcasting media" (p. 167). With this in mind, it becomes important for science teachers to emphasize the critical nature of the role of scientific communication, particularly when that communication might ultimately be disseminated by journalists for public consumption. Additionally, science teachers ought to underscore the importance of this communication as a means to overcome discourses of science mistrust that may be prevalent amongst certain subcultures of society. 
Though Canan and Hartman (2007) describe the importance of the "science-journalism collaboration", they acknowledge that several barriers persist between scientists and journalists that ultimately impede the ability for scientists to communicate effectively with journalists, resulting in "consequences on the quality of public knowledge regarding developments in science" (p. 167). In fact, Canan and Hartman (2007) indicate that these consequences can influence discourses of mistrust as communication barriers between scientists and journalists often stem from critical differences between the professional backgrounds of the two. Cultural, structural, and experiential differences between scientists and journalists may impede successful communication between the two groups, ultimately leading to the journalistic dissemination of scientific information that is not always readily consumed by certain subcultures of society.

Overcoming these communication barriers become a significant area of pedagogical exploration in science classrooms as developing future citizens who are able to communicate scientific information in effective ways might serve to overcome discourses of science mistrust in societies. Nicholas Russell (1991) proposes a communication project, known as the "common skills project", for science students wherein they must analyze "public perception and knowledge of science...the role of media in public understanding of scientific issues, and the position of the scientist... as a source of expert information" (p. 295) in the context of media publications related to science. In effect, science students are afforded an opportunity to develop a deeper understanding of the relationship between science and journalism, and explore ways in which the two sectors can help develop the public's understanding of scientific issues in a way that promotes the dissemination of factual, comprehensible scientific information to the public. Russell (1991) indicates that miscommunications that arise from the journalistic coverage of scientific information stem primarily from the general public's lack of knowledge of scientific facts and the scientific inquiry process; and that the general public's lack of knowledge in these two domains often results in discourses of science mistrust.

The "common skills project" requires students to purposefully evaluate collections of news coverage pieces related to a particular scientific phenomenon, and to think about how each piece supported their coverage of a scientific phenomenon with data, and how data interpretation was communicated by the author. Furthermore, the collection of news coverage pieces ought to be categorized by students as either broadsheet, middlemarket, or tabloid (Russell 1991), each describing the overall journalistic seriousness of the publication. Daniel Chandler and Rod Munday (2020) define the news coverage pieces as follows: broadsheet sources include those large newspapers targeting an elite audience of readers from the general public, middle-market sources include those publications that cater to readers looking for some entertainment value in addition to sufficient news coverage, and tabloid sources offer sensationalistic material that is primarily sought for its entertainment value. In congruence with the subject of this manuscript, student analysis of articles would be related exclusively to coverage of the COVID-19 pandemic.

In addition to providing students the opportunity to evaluate the factuality and validity of news coverage pieces related to scientific phenomena, Russell (1991) indicates that students ought to also evaluate the ways in which scientific information is subject to dramatization by journalists, in an effort to follow standard journalistic conventions requiring articles to possess a clearly defined beginning, middle, and end. In effect, in addition to the categorization and preliminary analysis of the scientific quality of news coverage pieces, students ought to further evaluate those pieces for their use of direct quotations from reputable scientific experts, as well as scientific diagrams and graphics. 
Finally, to aid students with understanding how valid scientific communication relies on the symbiotic relationship between science and journalism, Russell (1991) promotes the use of an activity, wherein students are required to translate a "scientific paper into a form which is informative for the general public" (p. 299) by preparing three articles based on the scientific phenomenon for broadsheet, middle-market, and tabloid publications. Providing students with this opportunity not only provide them with a better understanding of how to effectively communicate scientific information, but also the subjection of science to misinterpretation by journalists due to ineffective communication on behalf of the scientist; thereby perpetuating a discourse of science mistrust among subcultures of the general public.

As a best pedagogical practice, science educators might combine the evaluation of journalistic scientific coverage with the appraisal of sources for potential biases and conflicts of interest to ensure their students are best equipped with the skills necessary to obtain, evaluate, and communicate scientific information. It is important to note that the best pedagogical practice described serves as a "starting point" to overcome discourses of science mistrust. As the science classroom represents only a small part of the communities and contexts in which citizens operate, science educators ought to be mindful that their students might in fact belong to subcultures of society that permit, or propagate, discourses of science mistrust.

\section{Conclusion}

The COVID-19 pandemic produced a cultural phenomenon, wherein the general public suddenly became reliant on alternative forms of socialization due to widespread stay-athome orders across the nation. In-person socialization was replaced primarily with virtual social media postings and news broadcasts covering the progression of the pandemic. The public's sudden reliance on social media and news outlets for pandemic-related news led to the development of personal opinions that were not always rooted in science as a body of knowledge whose primary purpose is to aid with the public's understanding of the world around us, but rather rooted in a discourse of science mistrust.

This discourse of science mistrust was perpetuated by the same media vehicles that aimed to spread up-to-date coverage of the COVID-19 pandemic, and was even perpetuated by public officers in positions of trust. At the time of this writing, the result of this discourse of science mistrust was a surge in the number of coronavirus cases and deaths, that positioned the United States in the unenviable position of having a number of per capita cases and deaths in the top 10 countries on Earth (Johns Hopkins Coronavirus Resource Center 2020).

As evidenced by the surging number of coronavirus cases and deaths, it is indisputable that efforts ought to be taken in the science classroom to aid future populations with overcoming the discourse of science mistrust. By exploring the SEP of obtaining, evaluating, and communicating scientific information, I propose that science teachers provide their students with opportunities to evaluate sources of news for their reliability and validity, as well as opportunities to explore the complex relationship between science and journalism and what it means to effectively communicate scientific information such that the general public is able to trust its value. Doing so not only empowers students to effectively evaluate social media and news coverage of the COVID-19 pandemic, but also challenges the beliefs, values, and norms of those students who belong to subcultures that perpetuate 
discourses of science mistrust. Consequently, science classroom experiences that encourage students to obtain, evaluate, and communicate scientific information promote a future, wherein citizens are able to read, interpret, and critically consume scientific information in an effort to overcome discourses of science mistrust.

\section{References}

Adegboyega, A., Boddie, S., Dorvie, H., Bolaji, B., Adedoyin, C., \& Moore, S. E. (2020). Social distance impact on church gatherings: Socio-behavioral implications. Journal of Human Behavior in the Social Environment. https://doi.org/10.1080/10911359.2020.1793869

Ashton, J. (2021). COVID-19 and the anti-vaxxers. Journal of the Royal Society of Medicine, 114(1), 42-43. https://doi.org/10.1177/0141076820986065

Ball, P., \& Maxmen, A. (2020). The epic battle against coronavirus misinformation and conspiracy theories. Nature, 581(7809), 371-374. https://doi.org/10.1038/d41586-020-01452-z

Bendavid, E., Mulaney, B., Sood, N., Shah, S., Ling, E., Bromley-Delfano, R., Lai, C., Weissberg, Z., Saavedra-Walker, R., Tedrow, J., Tversky, D., Bogan, A., Kupiec, T., Eichner, D., Gupta, R., Ioannidis, J., \& Bhattacharya, J. (2020). COVID-19 antibody in Santa Clara county, California. MedRxiv. https:// doi.org/10.1101/2020.04.14.20062463

Benos, D. J., Fabres, J., Farmer, J., Gutierrez, J. P., Hennessy, K., Kosek, D., Joo, H. L., Olteanu, D., Russell, T., Shaikh, F., \& Kai, W. (2005). Ethics and scientific publication. Advances in Physiology Education, 29(1-4), 59-74. https://doi.org/10.1152/advan.00056.2004

Bhatia, G., \& Collet-White, M. (2020). Speed science: the risks of swiftly spreading coronavirus research [Infographic]. Reuters. https://graphics.reuters.com/CHINA-HEALTH-RESEARCH/0100B5ES3MG/ index.html

Bridgman, A., Merkley, E., Loewen, P. J., Owen, T., Ruths, D., Teichmann, L., \& Zhilin, O. (2020). The causes and consequences of COVID-19 misperceptions: understanding the role of news and social media. Misinformation Review. https://doi.org/10.37016/mr-2020-028

Canan, P., \& Hartman, M. (2007). Science-journalism collaboration: An experiment in closing the communication gap. Applied Environmental Education and Communication, 6(2), 167-177. https://doi.org/ $10.1080 / 15330150701598247$

Chandler, D., \& Munday, R. (2020). A dictionary of media and communication. (3rd ed.). Oxford University Press.

Charoenwong, B., Kwan, B., \& Pursiainen, V. (2020). Social connections with COVID-19 affected areas increase compliance with mobility restrictions. Science Advances, 6(47), 1-11. https://doi.org/10. 1126/sciadv.abc3054

Eikenberry, S. E., Mancuso, M., Iboi, E., Phan, T., Eikenberry, K., Kuang, Y., Kostelich, E., \& Gumel, A. B. (2020). To mask or not to mask: Modeling the potential for face mask use by the general public to curtail the COVID-19 pandemic. Infectious Disease Modeling, 5, 293-308. https://doi.org/10.1016/j. idm.2020.04.001

Harsin, J. (2020). Toxic White masculinity, post-truth politics and the COVID-19 infodemic. European Journal of Cultural Studies, 23(6), 1060-1068. https://doi.org/10.1177/1367549420944934

Johns Hopkins Coronavirus Resource Center. (2020). Cases and mortality by country . https://coronavirus. jhu.edu/data/mortality

Jurecki, K., \& Wander, M. C. F. (2012). Science literacy, critical thinking, and scientific literature: Guidelines for evaluating scientific literature in the classroom. Journal of Geoscience Education, 60(2), 100105. https://doi.org/10.5408/11-221.1

Landsverk, G. (2020, May 16). A controversial study on coronavirus was partly funded by an airline founder who's criticized lockdowns, according to a new investigation from BuzzFeed news. Business Insider. https://www.businessinsider.com/buzzfeed-stanford-coronavirus-study-funded-by-jetbluefounder-2020-5.

Lederman, J., \& O’Donnell, K. (2020, July 12). White house seeks to discredit Fauci amid coronavirus surge. CNBC. https://www.cnbc.com/2020/07/12/white-house-seeks-to-discredit-dr-anthony-fauci-ascoronavirus-surges.html.

Lee, S. A. (2020). Coronavirus anxiety scale: a brief mental health screener for COVID-19 related anxiety. Death Studies, 44(7), 393-401. https://doi.org/10.1080/07481187.2020.1748481

Miller, J. (2020). Do COVID-19 conspiracy theory beliefs form a monological belief system? Canadian Journal of Political Science, 53, 319-326. https://doi.org/10.1017/S0008423920000517 
Najmul Islam, A. K. M., Laato, S., Talukder, S., \& Sutinen, E. (2020). Misinformation sharing and social media fatigue during COVID-19: An affordance and cognitive load perspective. Technological Forecasting \& Social Change, 159, 1-14. https://doi.org/10.1016/j.techfore.2020.120201

NGSS Lead States. (2013). Next generation science standards: For states, by states. The National Academies Press.

Parmet, W. E., \& Paul, J. (2020). COVID-19: The first post-truth pandemic. American Journal of Public Health, 110(7), 945-946. https://doi.org/10.2105/AJPH.2020.305721

Russell, N. (1991). Science and the media: A communication project for science students. Journal of Biological Education, 25(4), 295-301. https://doi.org/10.1080/00219266.1991.9655228

Stover, S., \& Mabry, M. (2020). Evaluating information: the impact of major, class standing, and experience with primary literature. Journal of College Science Teaching, 49(3), 16-21

Union of Concerned Scientists. (2020, March 23). For coronavirus, federal scientists are restricted in what they can say to the public. https://www.ucsusa.org/resources/attacks-on-science/coronavirus-scien tists-are-what-they-can-say-public.

Union of Concerned Scientists. (2020, May 29). Trump administration ignores CDC scientists on COVID19 temperature screenings. https://www.ucsusa.org/resources/attacks-on-science/administration-ignor es-scientists-covid-19-temperature-screenings.

Xiao, S., \& Sandoval, W. (2017). Associations between attitudes towards science and children's evaluations of information about socio-scientific issues. Science \& Education, 26(3/4), 247-269. https://doi.org/ 10.1007/s11191-017-9888-0

Publisher's Note Springer Nature remains neutral with regard to jurisdictional claims in published maps and institutional affiliations.

Nancy Nasr is currently a secondary school chemistry educator with over seven years of experience in the diverse classroom. Teaching a population of approximately 50\% Latinx and Black students, Nancy's continued research interest is anchored in cultural responsiveness in the science classroom as well as student attitudes toward culturally responsive pedagogy. Additionally, Nancy has an interest in exploring the ways in which the Science and Engineering Practices (SEPs) of the NGSS can be used to infuse science learning that is situated in phenomena associated with social justice, and empowering her students to overcome social injustices through the use of science. 